\title{
Effect Through Broadcasting System Access Point For Video Transmission
}

\author{
Leni Marlina, Aswandi, Andysah Putera Utama Siahaan
}

\begin{abstract}
Most universities are already implementing wired and wireless network that is used to access integrated information systems and the Internet. At present, it is important to do research on the influence of the broadcasting system through the access point for video transmitter learning in the university area. At every university computer network through the access point must also use the cable in its implementation. These networks require cables that will connect and transmit data from one computer to another computer. While wireless networks of computers connected through radio waves. This research will be a test or assessment of how the influence of the network using the WLAN access point for video broadcasting means learning from the server to the client. Instructional video broadcasting from the server to the client via the access point will be used for video broadcasting means of learning. This study aims to understand how to build a wireless network by using an access point. It also builds a computer server as instructional videos, supporting software that can be used for video server that will be emitted by broadcasting via the access point and establish a system of transmitting video from the server to the client via the access point.
\end{abstract}

Keywords: Access Point, Broadcast, WLAN

\section{INTRODUCTION}

An access point is a half-duplex device that has the ingenuity, such as switching device. Wireless LAN administrators can configure and manage the device. As the name implies access point acts as a liaison so that the client can join into a network system. Computer network using wired and wireless. Network using a cable of course in actual need of cables that will connect and transmit data from one computer to another computer [1]. While wireless networks of computers connected through radio waves. Today the use of the network (networking) seemed to have become a staple in the world of work nor education. Network perceived simplify and make the work more effective. Some of the benefits of such networks are the sharing of the Internet, share files, share printers and run a multiplayer game. Perceived benefits of the network are still lacking and need to be developed further, and therefore in this research will be a test or assessment of how to use the WLAN network by using an access point for means of broadcasting video from the server to the client. Video is a collection of picture [6]. Broadcasting video from the server to the client via the access point will be used for video broadcasting means learning in universities which is expected to be used as a broadcast video broadcasting in a university community. However, the problem is now how to build this system to work as planned. It is necessary for the assessment, testing, and analysis of the system development process. Additionally, it will also be done review and search software support for video broadcasting process of learning through the access point. From the above description of this research will be focused discuss utilization access point for video transmitter learning area universities.

- Leni Marlina, Aswandi, Andysah Putera Utama Siahaan

- Faculty of Computer Science, Politeknik Negeri Lhokseumawe Jl. Banda Aceh - Medan Km. 220,3 Buketrata, 24301, Lhokseumawe, Indonesia

- Universitas Pembangunan Panca Budi Jl. Jend. Gatot Subroto Km. 4,5 Sei Sikambing, 20122, Medan, Sumatera Utara, Indonesia

- Iheny@pancabudi.ac.id, aswandi.mkom@gmail.com, andiesiahaan@gmail.com

\section{THEORIES}

\subsection{Broadcasting}

In this era of communication, use of communications technology is increasingly sophisticated. Therefore man should be able to adapt to the evolving science and technology around the life that was not called outdated. Developments in communication technology make the communication equipment communicate quickly. It can be felt today with the use of radio, TV, telephone, fax, mobile phone, computer, laptop, internet networks, the use of satellite communications and so on [2]. This innovation can help the needs of human life easier. This makes the world seems to be increasingly narrow even without the distance so that people can get information very quickly and easily from a very far distance, however. Even in provincial cities have already appeared several local TV equally compete for market audience, with the color of the grain which is designed as attractive as possible [5]. In the community has also come to a lot of production house working to produce a wide range of needs that require expertise and skills in the production of TV programs and advertising as well as other similar needs of both business and public services. With the emergence of various broadcasters in each region, it also appears the rules restricting the broadcasting coverage, which is related to regional autonomy will be possible to apply the rules to increase local revenue so that broadcasters should be designed to be local. In other words, those who exceed the limit radius of an area, there must be consequences imposed local taxes. It will further spur the growth and development of local broadcasters, due to large broadcasters that are already national will be hampered by local regulations.

\subsection{Wireless Network}

In the late 1970s, IBM released the results of their experiments in designing a WLAN with IR technology, other companies such as Hewlett-Packard (HP) test WLAN RF. Both of these companies only achieve a data rate of 100 Kbps. Because it does not meet the standard IEEE 802 for LAN that is $1 \mathrm{Mbps}$, the products are not marketed. Only in 1985, (FCC) set the tape Industrial, Scientific and Medical (ISM band) is $902-928 \mathrm{MHz}, 2400-2483.5 \mathrm{MHz}$, and 5725$5850 \mathrm{MHz}$ are unlicensed, so the development of commercial 
WLAN entering a serious stage. It was only in 1990 WLAN can be marketed with a product that uses spread spectrum techniques (SS) in the ISM band, unlicensed frequency 18$19 \mathrm{GHz}$ and IR technology with a data rate> 1 Mbps. In 1997 , an independent agency called the IEEE created a specification / standard WLAN 802.11 first coded. Appropriate equipment 802.11 standards can work in the $2.4 \mathrm{GHz}$ frequency, and the data transfer rate (throughput) theoretical maximum of 2 Mbps. In July 1999, IEEE re-issued a new specification called $802.11 \mathrm{~b}$. Maximum theoretical data transfer speeds that can be achieved is $11 \mathrm{Mbps}$. The speed of data transfer is comparable to traditional Ethernet (IEEE $802.310 \mathrm{Mbps}$ or 10Base-T). The equipment uses the $802.11 \mathrm{~b}$ standard also works at a frequency of $2.4 \mathrm{GHz}$. One drawback of wireless equipment working at this frequency is the possibility of interference with cordless phones, microwave ovens, or other devices that use radio waves on the same frequency. At that same time, IEEE 802.11a specification which makes use of different techniques. $5 \mathrm{GHz}$ frequency used and supports a maximum theoretical data transfer speeds up to $54 \mathrm{Mbps}$. The radio waves emitted by 802.11a equipment is relatively difficult to penetrate walls or other obstructions. Range radio waves are relatively shorter than $802.11 \mathrm{~b}$. Technically, $802.11 \mathrm{~b}$ is not compatible with 802.11a. However, today is pretty much hardware factory that makes equipment that supports both these standards [3]. In 2002, the IEEE created a new specification that can combine the advantages of $802.11 \mathrm{~b}$ and $802.11 \mathrm{a}$. $802.11 \mathrm{~g}$ specification coded works at a frequency of $2.4 \mathrm{GHz}$ with a maximum theoretical data transfer rate of $54 \mathrm{Mbps} .802 .11 \mathrm{~g}$ is compatible with $802.11 \mathrm{~b}$ equipment so that it can be interchangeable. Let's say a computer that uses the $802.11 \mathrm{~g}$ network cards can utilize the $802.11 \mathrm{~b}$ access point, and vice versa. In 2006, 802.11n technology developed by combining 802.11b, 802.11g. Technology that carried known as MIMO (Multiple Input Multiple Output) is the latest Wi-Fi technology. MIMO is based on the Pre-802.11n specification. The word "Pre-" states "standard versions of 802.11n". MIMO offers increased throughput, superior reliability, and increased the number of clients that are connected. MIMO penetrating power against the better barrier, besides wider range so that you can put a laptop or Wi-Fi clients at will. MIMO Access Point can reach a variety of $\mathrm{Wi}-\mathrm{Fi}$ equipment imaginable in every corner of the room. MIMO is technically superior to his elder brother 802.11a / b / g. MIMO Access Point can recognize radio waves emitted by the $\mathrm{Wi}-\mathrm{Fi}$ adapter $802.11 \mathrm{a}$ / b / g. MIMO support backward compatibility with 802.11 a / b / g. MIMO Wi-Fi equipment can generate a data transfer speed of $108 \mathrm{Mbps}$.

\subsection{Quality of Service}

A quality of service is a concept that aims to qualify the user satisfaction about an application offered and did not look at any of the network used, because the principles are the same, including network-based applications that use TCP / IP. A quality of service means providing superior service, service that can meet or even exceed user expectations. So the quality of service is called good if there is no gap between user expectations with actual service they receive [4]. In the development of a fast network, the concept of Quality of Service (QoS) is undefined by default, but, has the same concept, and an assortment of theories / understanding that exists is taking a packet of data to the destination is the major and note. Interest carry data packets to the destination with the "good result" is a simple form of quality of service. Quality of Service is a generic term the which takes account info Several techniques and strategies that could assure a predictable application and service users from the network and other components Involved, such as operating systems. According to the Trillium Digital Systems (1998), CCITT Recommendation E.800 about the quality of service (QOS-Quality of Service) mentions that the quality of service is: "The collective performance of service roommates determines the degree of satisfaction of a user of the service." By this definition, means that the quality of service depends on customer perception of the service received. However, in the provision of the network, there should be a quantitative measure of the characteristics of the service, so customers can estimate the class of service they will receive. QoS stands for Quality of Service. It is a measure of how well the network and is an attempt to define the characteristics and properties of a service. QoS is typically used to measure the performance of a set of attributes that have been specified and is usually associated with a service. In IPbased networks, IP QoS refers to the performance of the IP packets passing through one or more networks. QoS is designed to help end users become more productive by making sure that he gets a reliable performance of networkbased applications. QoS refers to the ability of a network to provide better service to a specific network traffic through different technologies. QoS is a big enough challenge in IPbased networks and the Internet as a whole. The goal of QoS is to satisfy the needs of different services, which use the same infrastructure. QoS offers the ability to define the attributes of the network services provided, both qualitatively and quantitatively. QoS is a term used to define the ability of a network to provide the level of service guarantee is different. Through QOS, a network administrator can give priority to certain traffic. A network may consist of one or several data link layer technologies that can implement QoS, for example; Frame Relay, Ethernet, Token Ring, Point-toPoint Protocol (PPP), HDLC, X.25, ATM, SONET. Each technology has different characteristics that should be considered when implementing QoS. QoS can be implemented in a situation congestion management or congestion avoidance. Congestion management techniques used to organize and prioritize traffic on a network where applications are demanding more bandwidth than can be provided by the network. By implementing the priorities on the various classes of traffic, congestion management techniques to optimize business critical applications or delay sensitive to be able to operate as it should in the network environment that has congestion. The collision avoidance techniques will make the technology mechanism to avoid congestion situation. Through the implementation of QoS in the network, the network administrator will have the flexibility to control the flow and the events in the traffic on the network.

\section{Methodology}

The instrument used to determine the effect of a service quality broadcasting system through a media access point as instructional video transmitter that is used to collect data from the study has been developed using parameters Quality of Services (QoS) in the ITU G.711 standard. There are several factors that affect the quality of service of the learning video 
broadcasting systems such as the time delay, packet loss and the type of codec. Then the video file size and allocation of network capacity will also affect the quality of the service as a whole. Results collected data from such parameters as the testing conducted during the implementation of the system. In this study using two techniques of data analysis, namely 1) descriptive analysis of qualitative and quantitative descriptive statistical analysis. Qualitative descriptive analysis technique is used to process the test results in this study, descriptive statistical analysis techniques used to process the data obtained through the numbers in the form of the descriptive percentage. The formula used to calculate Throughput is as follows:

$$
\text { Throughput }=\frac{\text { TotalBytes }}{\text { Duration }}
$$

Where:

$$
\begin{array}{ll}
\text { TotalBytes } & =\text { Total bits sent } \\
\text { Duration } & =\text { Total packet time }
\end{array}
$$

The total of lost packets may occur due to collisions and congestion on the network, and it affects all applications for retransmission will reduce overall network efficiency despite ample amount of bandwidth available for these applications. The network device has a buffer to store data received. If congestion is long enough, the buffer will be full, and the new data will not be accepted. Loss packages, the number of data packets were lost during transmission process.

$$
\text { PLoss }=\frac{\text { PSent }- \text { PReceived }}{\text { Psent }} * 100 \%
$$

Where:

$$
\begin{array}{ll}
\text { PSent } & =\text { total UDP packets transmitted } \\
\text { PReceived } & =\text { packets successfully received }
\end{array}
$$

In the parameters of Quality of Services (QoS) in the ITU G.711 standard divides the characteristics of the delay time based on the level of user convenience, it can be shown in Table 1 and 2.

Tabel 1. Packet Loss

\begin{tabular}{|c|c|}
\hline PACKET LOSS & CATEGORY \\
\hline 0 & Excellent \\
\hline 3 & Good \\
\hline 15 & Average \\
\hline 25 & Bad \\
\hline
\end{tabular}

The time needed to cover the distance from the data source (server) to the destination (client) is known as Delay.

$$
\text { Delay }=\frac{\text { Duration }}{\text { TotalPackets }}
$$

Where:

Duration $=$ total time package delivery

Total Packets $=$ total packets sent

Tabel 2. Delay illustration

\begin{tabular}{|c|c|}
\hline DELAY TIME & QUALITY \\
\hline$<150 \mathrm{~ms}$ & Excellent \\
\hline $150 \mathrm{~s} / \mathrm{d} 300 \mathrm{~ms}$ & Good \\
\hline $300 \mathrm{~s} / \mathrm{d} 450 \mathrm{~ms}$ & Average \\
\hline$>450 \mathrm{~ms}$ & Bad \\
\hline
\end{tabular}

\section{Evaluation}

This research will be built by the system architecture at the some universities area. Architecture is a representation that allows Software Engineer to analyze the effectiveness of the design on the terms that have been defined, considering the architectural alternatives at a level as to make an amendment-is still relatively easy design changes, reducing the risks associated with the construction software. The design of the video transmitter system architecture depicted in Figure 1.

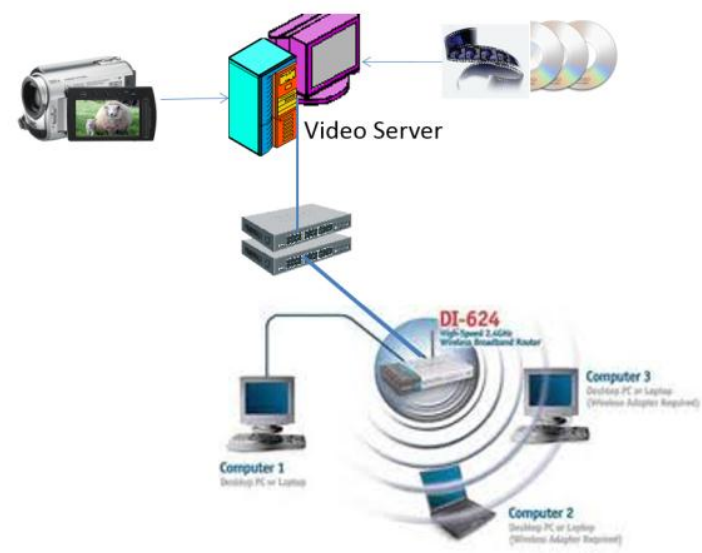

Fig. 1 Video transmitter system architecture

To view streaming video or instructional videos can be viewed online using the web browser by opening a link IP address that is already configured on the server side before, this can be seen as the following figure.

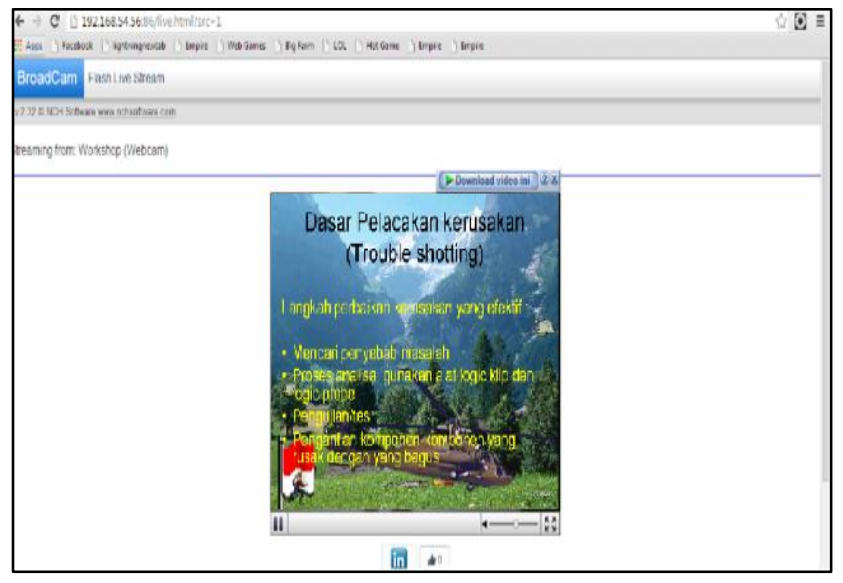

Fig. 2 Video learning result

In testing the results of this study following the system architecture for distributing video on the university campus area development Panca Budi Medan. The observations of the quality video distribution is done on a local network with a speed of $100 \mathrm{Mbps}$ at the level of video compression on the default setting for:

a. Low Quality $768 \times 576$ resolution, and frame rate of 15 fps

b. High Quality $768 \times 576$ resolution, and frame rate of 25 fps 


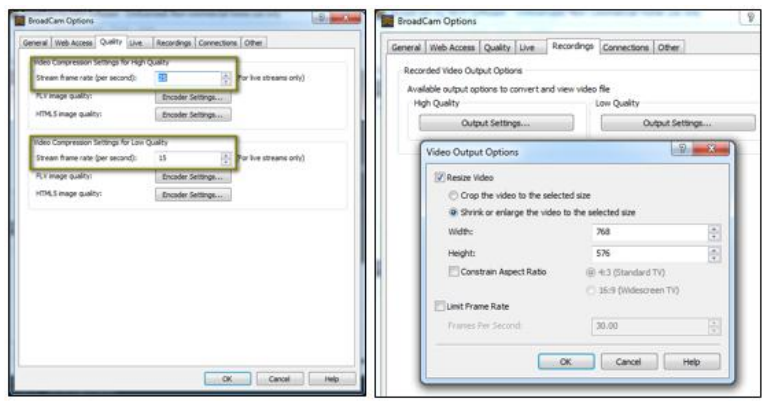

Fig. 3 Quality option

Figure 3 describe the options can be taken to perform the video streaming.

\subsection{Observations Deployment}

From the results of observations made while testing is done by accessing the instructional video using one user, five users and ten users. The observations were carried out to measure the quality of video distribution as follows: Spreading Video Quality Testing using one user accessing instructional video services on a local network using the access point.

Table 3. Observations quality video spread of learning

\begin{tabular}{|c|c|c|c|c|}
\hline Frame Rate & Throughput & Paket Loss & Delay & $\begin{array}{c}\text { Keterangan } \\
\text { Video }\end{array}$ \\
\hline $15 \mathrm{fps}$ & $115 \mathrm{Mbps}$ & $2,15 \%$ & $110,61 \mathrm{~ms}$ & Sangat Bagus \\
\hline $25 \mathrm{fps}$ & $90 \mathrm{Mbps}$ & $7,23 \%$ & $190,74 \mathrm{~ms}$ & Bagus \\
\hline
\end{tabular}

Table 3 shows that the results of testing the quality of learning for the deployment of video bandwidth of $100 \mathrm{Mbps}$ already meet the standards of a very good quality. Spreading Video Quality Testing using five users accessing instructional video services on a local network using the access point.

Table 4. Observations quality video spread of learning

\begin{tabular}{|c|c|c|c|c|}
\hline $\begin{array}{c}\text { Frame } \\
\text { Rate }\end{array}$ & $\begin{array}{c}\text { Through } \\
\text { put }\end{array}$ & $\begin{array}{l}\text { Paket } \\
\text { Loss }\end{array}$ & Delay & $\begin{array}{l}\text { Keterangan } \\
\text { Video }\end{array}$ \\
\hline \multirow{5}{*}{$15 \mathrm{fps}$} & $98 \mathrm{Mbps}$ & $2,75 \%$ & $130,60 \mathrm{~ms}$ & \multirow{5}{*}{$\begin{array}{l}\text { Sangat } \\
\text { Bagus }\end{array}$} \\
\hline & $98 \mathrm{Mbps}$ & $2,81 \%$ & $130,70 \mathrm{~ms}$ & \\
\hline & $97 \mathrm{Mbps}$ & $2,83 \%$ & $130,75 \mathrm{~ms}$ & \\
\hline & $97 \mathrm{Mbps}$ & $2,87 \%$ & $140,12 \mathrm{~ms}$ & \\
\hline & $96 \mathrm{Mbps}$ & $2,88 \%$ & $140,60 \mathrm{~ms}$ & \\
\hline \multirow{5}{*}{$25 \mathrm{fps}$} & $80 \mathrm{Mbps}$ & $13,82 \%$ & $137,31 \mathrm{~ms}$ & \multirow{5}{*}{ Bagus } \\
\hline & $79 \mathrm{Mbps}$ & $13,82 \%$ & $139,73 \mathrm{~ms}$ & \\
\hline & 79 Mbps & $13,95 \%$ & $139,97 \mathrm{~ms}$ & \\
\hline & $78 \mathrm{Mbps}$ & $14,13 \%$ & $140,12 \mathrm{~ms}$ & \\
\hline & $76 \mathrm{Mbps}$ & $14,32 \%$ & $140,60 \mathrm{~ms}$ & \\
\hline
\end{tabular}

Table 5 shows that the results of testing the quality of learning for the deployment of video bandwidth of $100 \mathrm{Mbps}$ already meet the standards of a very good quality. Spreading Video Quality Testing using ten users accessing instructional video services on a local network using the access point.
Table 5. Observations quality video spread of learning

\begin{tabular}{|c|c|c|c|c|}
\hline $\begin{array}{c}\text { Frame } \\
\text { Rate }\end{array}$ & $\begin{array}{c}\text { Through } \\
\text { put }\end{array}$ & $\begin{array}{l}\text { Paket } \\
\text { Loss }\end{array}$ & Delay & $\begin{array}{c}\text { Keterangan } \\
\text { Video }\end{array}$ \\
\hline \multirow{10}{*}{$15 \mathrm{fps}$} & $88 \mathrm{Mbps}$ & $3,15 \%$ & $159,96 \mathrm{~ms}$ & \multirow{10}{*}{ Bagus } \\
\hline & $88 \mathrm{Mbps}$ & $3,31 \%$ & $160,12 \mathrm{~ms}$ & \\
\hline & $88 \mathrm{Mbps}$ & $3,50 \%$ & $160,35 \mathrm{~ms}$ & \\
\hline & $87 \mathrm{Mbps}$ & $3,76 \%$ & $162,76 \mathrm{~ms}$ & \\
\hline & $87 \mathrm{Mbps}$ & $3,85 \%$ & $171,77 \mathrm{~ms}$ & \\
\hline & $86 \mathrm{Mbps}$ & $4,05 \%$ & $171,93 \mathrm{~ms}$ & \\
\hline & $86 \mathrm{Mbps}$ & $4,31 \%$ & $177,17 \mathrm{~ms}$ & \\
\hline & $86 \mathrm{Mbps}$ & $4,40 \%$ & $178,75 \mathrm{~ms}$ & \\
\hline & $85 \mathrm{Mbps}$ & $4,76 \%$ & $200,57 \mathrm{~ms}$ & \\
\hline & $85 \mathrm{Mbps}$ & $4,85 \%$ & $202,62 \mathrm{~ms}$ & \\
\hline \multirow{10}{*}{$25 \mathrm{fps}$} & $70 \mathrm{Mbps}$ & $17,32 \%$ & $340,60 \mathrm{~ms}$ & \multirow{10}{*}{ Sedang } \\
\hline & $69 \mathrm{Mbps}$ & $17,43 \%$ & $349,12 \mathrm{~ms}$ & \\
\hline & $69 \mathrm{Mbps}$ & $18,45 \%$ & $367,97 \mathrm{~ms}$ & \\
\hline & $68 \mathrm{Mbps}$ & $19,82 \%$ & $389,73 \mathrm{~ms}$ & \\
\hline & $68 \mathrm{Mbps}$ & $20,92 \%$ & $402,31 \mathrm{~ms}$ & \\
\hline & $67 \mathrm{Mbps}$ & $26,32 \%$ & $405,60 \mathrm{~ms}$ & \\
\hline & $66 \mathrm{Mbps}$ & $26,53 \%$ & $408,12 \mathrm{~ms}$ & \\
\hline & $65 \mathrm{Mbps}$ & $26,95 \%$ & $419,97 \mathrm{~ms}$ & \\
\hline & $64 \mathrm{Mbps}$ & $27,22 \%$ & $429,73 \mathrm{~ms}$ & \\
\hline & $64 \mathrm{Mbps}$ & $27,82 \%$ & $430,31 \mathrm{~ms}$ & \\
\hline
\end{tabular}

Table 5 shows that the results of testing the quality of learning for the deployment of video bandwidth of $100 \mathrm{Mbps}$ already meet the standard of good quality.

\subsection{Observations In Graph Spreading Quality Video Learning}

In testing the results of this study by the system architecture for distributing video in the university area. In observation of the quality of the video deployment graphically burdened with users who access the streaming video service with a growing number, from 1 up to 10 users.

\section{Throughput}

Deployment of Video Quality test results that can be accessed by the user together then obtained throughput value ratio shown in Figure 4 and 5 .

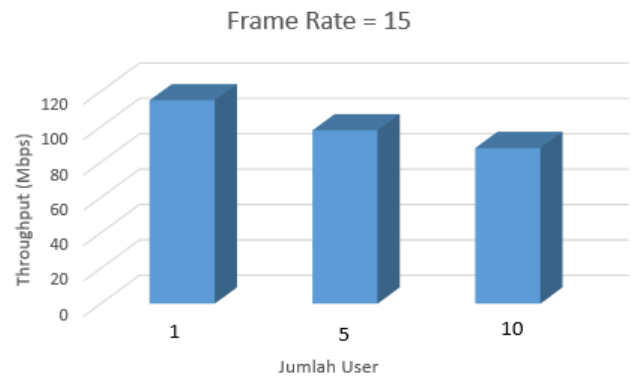

Fig. 4 Throughput Frame Rate $=15$

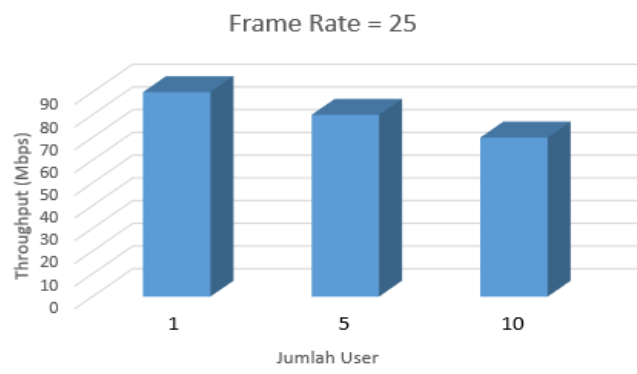

Fig. 5 Throughput Frame Rate $=25$ 


\section{Delay}

Deployment of Video Quality test results that can be accessed by the user together then obtained Delay value comparison shown in Figure 6 and 7.

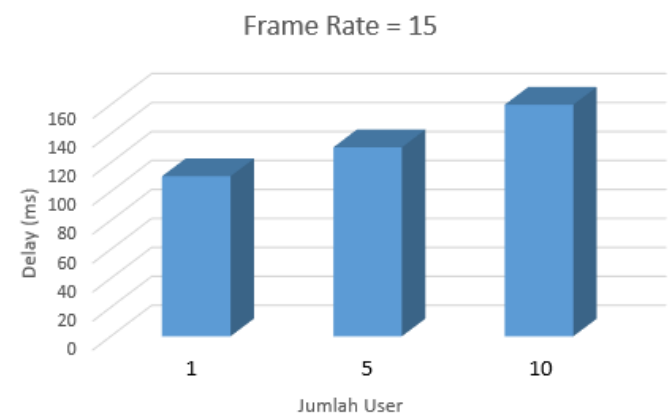

Fig. 6 Delay Frame Rate $=15$

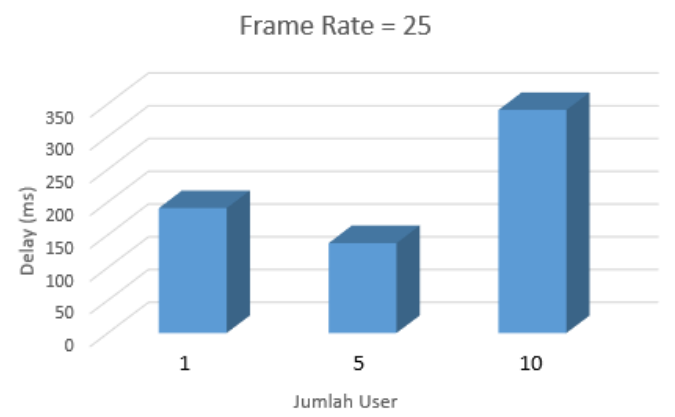

Fig. 7 Delay Frame Rate $=15$

\section{Packet Loss}

Deployment of Video Quality test results that can be accessed by the user together then obtained Loss Package value comparison is shown in Figure 8 and 9.

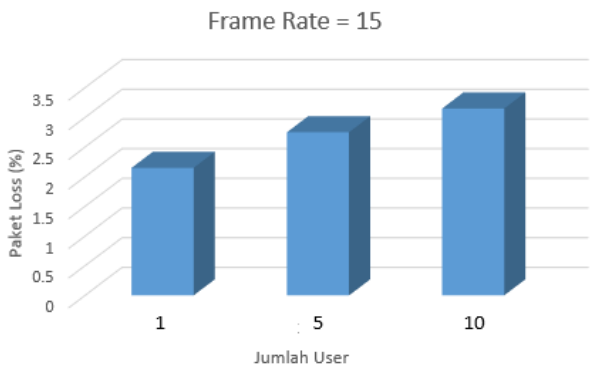

Fig. 8 Packet Loss Frame Rate $=15$

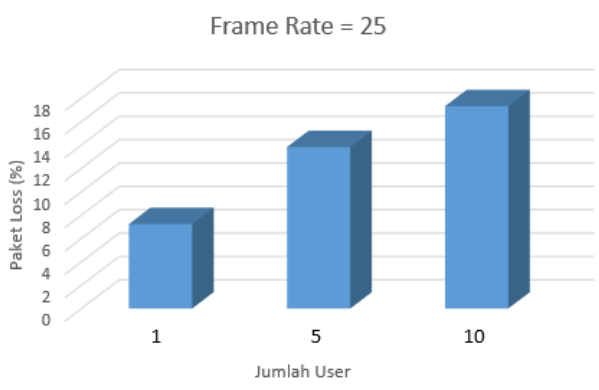

Fig. 9 Packet Loss Frame Rate $=25$

\section{CONCLUSION}

Based on the results of the implementation of the research is analyzed, it can be concluded that the test is carried out by the number of frame rate provided by the application program instructional video that is 15 and 25 frame rate. Tests carried out by one user to ten users then the result is said to be very good with using frame rate 15 . The tests were conducted starting from one user up to ten users; the results have been quite good using frame rate 25 . The video frame rate of learning that transmitted using access point on the LAN network is affected by the number of users, the more users connected to the server, the worse the results of streaming video services. It is caused by the decrease in overall throughput, as well as increased delay, which ultimately impacts on increasing the percentage of packet loss.

\section{REFERENCES}

[1] R. S. Geiger and A. Lampinen, "Old Against New, or a Coming of Age? Broadcasting in an Era of Electronic Media," Journal of Broadcasting \& Electronic Media, vol. 58, no. 3, pp. 333-341, 2014.

[2] L. Baruh, "Publicized Intimacies on Reality Television: An Analysis of Voyeuristic Content and Its Contribution to the Appeal of Reality Programming," Journal of Broadcasting \& Electronic Media5, vol. 53, no. 2, pp. 190-210, 2009.

[3] J. Foote and D. Kimber, "Practical Panoramic Video," in Proc. of IEEE International Conference on Multimedia and Expo, 2006.

[4] J. Benesty, "Adaptive Eigenvalue Decomposition Algorithm for Passive Acoustic Source Localization," Journal of Acoustics of America, vol. 107, pp. 384391, 2000.

[5] W. Fischer, Digital Video and Audio Broadcasting Technology: A Practical Engineering Guide, vol. 6, Berlin: Springer Berlin Heidelberg, 2010, pp. 697704.

[6] A. P. U. Siahaan, "RC4 Technique in Visual Cryptography RGB Image Encryption," International Journal of Computer Science and Engineering, vol. 3, no. 7, pp. 1-6, 2016. 